\title{
Identification of three novel polymorphisms in the MJD1 gene and study of their frequency in the Portuguese population
}

Received: December 19, 2001 / Accepted: January 28, 2002

\begin{abstract}
Machado-Joseph disease (MJD) is an autosomal dominant neurodegenerative disorder of late onset, caused by the expansion of a $(\mathrm{CAG})_{\mathrm{n}}$ tract in the MJD1 gene. Using $B L A S T 2$ sequences between known cDNA variants transcribed by the MJD1 gene and a clone of human genomic DNA, six possible unknown intragenic singlenucleotide polymorphisms (SNPs), at variable positions in the MJD1 gene, were identified. To confirm this, we studied a Portuguese control population, using polymerase chain reaction amplification and single-strand conformation polymorphism analysis for each potential SNP. For four of the possible polymorphisms there was no variability in our population, but the existence of three novel polymorphisms was confirmed: $\mathrm{GTT}^{527} / \mathrm{GTC}^{527}, \mathrm{C}^{1178} / \underline{\mathrm{A}}^{1178}$, and $\underline{\mathrm{A}}^{1294} /$ $\underline{\mathrm{G}}^{1294}$. The polymorphism $\mathrm{GTT}^{527} / \mathrm{GTC}^{527}$ (Val/ Val) is located in the coding region, whereas $\underline{C}^{1178} / \underline{A}^{1178}$ and $\underline{A}^{1294} / \underline{G}^{1294}$ are located in the 3 'noncoding region of cDNA variants of the MJD1 gene, MJD2-1 and MJD1-1, respectively. All these novel SNPs are in Hardy-Weinberg equilibrium. These intragenic polymorphisms can be useful for (1) the study of the origin of the MJD mutation(s), (2) the study of recombination events, (3) distinction of chromosomes with alleles of identical $(\mathrm{CAG})_{\mathrm{n}}$ size in genetic tests (homoallelism), (4) the study of genetic modifiers in the region flanking the MJD1 gene, and (5) association studies in other diseases.
\end{abstract}

Key words Polymorphism · Genetic diversity · Trinucleotide repeats . Machado-Joseph disease . Neurodegenerative disorder

M. do Carmo Costa $(\varangle) \cdot$ J. Sequeiros $\cdot$ P. Maciel

UnIGENe, IBMC, Universidade do Porto, 4150-180 Porto, Portugal

Tel. +351-22-6074942; Fax +351-22-6099157

e-mail: ccosta@ibmc.up.pt

J. Sequeiros · P. Maciel

Departamento de Estudos das Populações, ICBAS, Universidade do

Porto, Porto, Portugal

\section{Introduction}

Machado-Joseph disease (MJD) is an autosomal dominant neurodegenerative disorder of late onset, characterized by cerebellar ataxia, progressive external ophthalmoplegia, and pyramidal signs (Coutinho and Andrade 1978). The causative mutation is the expansion of a $(\mathrm{CAG})_{\mathrm{n}}$ tract in the MJD1 gene, localized on 14q32.1 (Kawaguchi et al. 1994): 12-44 repeats in normal genes and 53-87 repeats in mutated genes.

Three intragenic single-nucleotide polymorphisms (SNPs) are already known in the MJD1 gene: $\underline{\mathrm{A}}^{669} \mathrm{TG} /$ $\underline{\mathrm{G}}^{669} \mathrm{TG}, \underline{\underline{ }}^{987} \mathrm{GG} / \underline{G}^{987} \mathrm{GG}$, and TA$\underline{A}^{1118} / \mathrm{TA} \underline{C}^{1118}$ (Goto et al. 1997). These intragenic SNPs were used in a worldwide haplotype study to elucidate the ancestral origins of the MJD mutation, which demonstrated haplotype $A^{669}-C^{987}$ $\mathrm{A}^{1118}$ to be shared by the majority of the families studied, suggesting a major founder mutation in MJD (Gaspar et al. 2001; Lima et al. 1998). The intragenic polymorphism $\underline{C}^{987} \mathrm{GG} / \underline{G}^{987} \mathrm{GG}$ has been implicated in intergenerational instability when present in cis or in trans of the CAG expansion causative of MJD (Igarashi et al. 1996; Maciel et al. 1999).

To further characterize the MJD1 gene, we studied a Portuguese control population for variability in specific regions of the gene where, by bioinformatics, the existence of novel SNPs was indicated. These SNPs could contribute to the study of the origin of the MJD mutation, the study of the molecular mechanisms for the instability of CAG repeats, and the characterization of the MJD1 gene in the Portuguese population.

\section{Subjects and methods}

A Portuguese control population of 76 individuals was studied. Samples were obtained in a random and anonymous manner from all 20 regions of Portugal, including the Azores and Madeira Islands. Genomic DNA was isolated 
Table 1. Primers and annealing temperature used for amplification, by PCR, of the DNA fragment containing each of the new intragenic polymorphisms in the MJD1 gene

\begin{tabular}{lll}
\hline $\begin{array}{l}\text { Intragenic polymorphism } \\
\text { in the MJD1 gene }\end{array}$ & Primers used in the PCR reaction & $\begin{array}{l}\text { Annealing } \\
\text { temperature }\end{array}$ \\
\hline $\mathrm{GT}^{527} / \mathrm{GTC}^{527}$ & $\begin{array}{l}\text { MJD13: 5'GGAGTTGGTCAGCTTCGCAAT } \\
\text { MJD19: 5'CCAGTGTTCTGTGCTGCCTTTT }\end{array}$ & $61^{\circ} \mathrm{C}$ \\
$\underline{\mathrm{C}}^{1178} / \underline{\mathrm{A}}^{1178}$ & $\begin{array}{l}\text { MJD7: 5'GCTCCTTAATCCAGGGAAATTTAG } \\
\text { MJD20: 5'AGCTCCATGTGATTTTGCT }\end{array}$ & $59^{\circ} \mathrm{C}$ \\
$\underline{\mathrm{A}}^{1294} / \underline{\mathrm{G}}^{1294}$ & $\begin{array}{l}\text { MJD14: 5'AGGAAATAAGACTTTTAGCGGTTTGC } \\
\text { MJD15: 5'GGCTAATATTTGGAAGATCA }\end{array}$ & $61^{\circ} \mathrm{C}$ \\
\hline
\end{tabular}

PCR, Polymerase chain reaction

from peripheral blood in Guthrie cards, normally used for newborn screening of phenylketonuria and congenital hypothyroidism, using Chelex (BioRad) in a final concentration of $0.8 \%$.

A multiple alignment (BLAST2 sequences) was made between the known cDNA variants transcribed by the MJD1 gene (Goto et al. 1997) and a clone of human genomic DNA from chromosome 14, BAC R-529H20 (accession number AL049723). This comparison suggested the possible existence of six previously unknown intragenic SNPs at variable positions in the MJD1 gene.

To confirm the existence of the six possible intragenic polymorphisms, we amplified a fragment of the MJD1 gene by polymerase chain reaction (PCR), using the specific primers for each SNP, and the same conditions as described for amplification of the CAG repeat (Kawaguchi et al. 1994), except for the annealing temperature (see Table 1 for primer sequence and annealing temperature). The amplified fragments were analyzed by single-strand conformation polymorphism (SSCP), using a nondenaturing 7\% polyacrylamide gel at $4^{\circ} \mathrm{C}$, and visualized by autoradiography. Confirmation of the sequence variants was obtained using DNA from individuals with different patterns of migration as obtained by SSCP. DNA sequencing was performed using the Thermo Sequenase Cycle Sequencing kit (Amersham Pharmacia Biotech, Cleveland, USA) following the instructions of the manufacturer. The SNPs $\underline{C}^{1178}$ / $\underline{\mathrm{A}}^{1178}$ and $\underline{\mathrm{A}}^{1294} / \underline{\mathrm{G}}^{1294}$ can also be detected by PCR-restriction fragment length polymorphism: in the first case the restriction enzyme PleI recognizes the allele $\underline{\mathrm{C}}$ but not the $\underline{\mathrm{A}}$, and in the second case the restriction enzyme $N s i$ I recognizes the allele $\underline{\mathrm{A}}$ but not the $\underline{\mathrm{G}}$.

The Hardy-Weinberg equilibrium was evaluated with a $\chi^{2}$ test. The degree of polymorphism was measured by the polymorphism information content (PIC) value.

\section{Results}

Six novel potential intragenic polymorphisms in the MJD1 gene were identified by bioinformatics: $\mathrm{GTT}^{527} / \mathrm{GTC}^{527}$, $\underline{\mathrm{G}}^{789} \mathrm{CT} / \underline{\mathrm{A}}^{789} \mathrm{CT}, \quad \underline{\mathrm{C}}^{1178} / \underline{\mathrm{A}}^{1178}, \quad \underline{\mathrm{C}}^{1293} / \underline{\mathrm{T}}^{1293}, \quad \underline{\mathrm{G}}^{1297} / \underline{\mathrm{A}}^{1297}, \quad$ and $\underline{\mathrm{A}}^{1360} / \underline{T}^{1360}$.

For four of the possible polymorphisms $-\underline{\mathrm{G}}^{789} \mathrm{CT} /$ $\underline{\mathrm{A}}^{789} \mathrm{CT}, \underline{\mathrm{C}}^{1293} / \underline{\mathrm{T}}^{1293}, \underline{\mathrm{G}}^{1297} / \underline{\mathrm{A}}^{1297}$, and $\underline{\mathrm{A}}^{1360} / \underline{\mathrm{T}}^{1360}$ - there was no variability in the population studied. The existence of variability for the other two SNPs, GTT $\underline{T}^{527} / \mathrm{GT} \underline{C}^{527}$ and $\underline{C}^{1178}$ / $\underline{\mathrm{A}}^{1178}$, was confirmed in this population. Sequencing excluded the existence of the SNPs $\underline{C}^{1293} / \underline{T}^{1293}$ and $\underline{G}^{1297} / \underline{A}^{1297}$, but confirmed the existence of another SNP, $\underline{A}^{1294} / \underline{G}^{1294}$ (Fig. 1). In conclusion, we identified three novel SNPs in the MJD1 gene: $\mathrm{GTT} \underline{\mathrm{T}}^{527} / \mathrm{GT} \underline{\mathrm{C}}^{527}, \underline{\mathrm{C}}^{1178} / \underline{\mathrm{A}}^{1178}$, and $\underline{\mathrm{A}}^{1294} / \underline{\mathrm{G}}^{1294}$. Their respective frequencies in the population studied were T/T: 0.18, C/C: 0.42, and T/C: 0.40 (PIC = 0.36); C/C: 0.04, A/A: 0.71, and C/A: $0.25(\mathrm{PIC}=0.24)$; and A/A: 0.03, G/G: 0.71 , and $\mathrm{A} / \mathrm{G}$ : 0.26 ( $\mathrm{PIC}=0.23)$. All were in HardyWeinberg equilibrium $(P>0.9)$.

The SNPs GTT ${ }^{527} / \mathrm{GTC}^{527}, \underline{\mathrm{C}}^{1178} / \underline{\mathrm{A}}^{1178}$, and $\underline{\mathrm{A}}^{1294} / \underline{\mathrm{G}}^{1294}$ were submitted to the National Center for Biotechnology Information dbSNP and their respective accession numbers are 4325102, 4325101, and 4325103.

Given that we tested unrelated individuals in a control sample, it was not possible to determine the phase of chromosomes, and we could not at this point detect if the intragenic polymorphisms are in linkage disequilibrium or not.

\section{Discussion}

In addition to the three previously known intragenic polymorphisms present in this gene, we identified three novel polymorphisms: $\mathrm{GTT}^{527} / \mathrm{GTC} \underline{C}^{527}$ (Val/Val) located in the coding region, and $\underline{C}^{1178} / \underline{\mathrm{A}}^{1178}$ and $\underline{\mathrm{A}}^{1294} / \underline{\mathrm{G}}^{1294}$ located in the 3'noncoding region of cDNA variants MJD2-1/MJD1a and MJD1-1/MJD5-1 (Goto et al. 1997; Ichikawa et al. 2001), respectively.

These intragenic polymorphisms can be useful for (1) the study of the origin of the MJD mutation(s), namely, to broaden the haplotypes in study, since these novel SNPs flank those used in previous studies (Gaspar et al. 2001) at both the 5' and $3^{\prime}$ sides; (2) the study of recombination events (proposed by several authors to be involved in the instability of trinucleotide repeats); (3) distinction of chromosomes with alleles of identical $(\mathrm{CAG})_{\mathrm{n}}$ size in genetic tests (homoallelism) - in particular, the polymorphism $\underline{\mathrm{C}}^{1178} / \underline{\mathrm{A}}^{1178}$ has been applied to the improvement of the molecular diagnosis of MJD (Maciel et al. 2001); (4) the study of genetic modifiers in the region flanking the MJD1 gene; and (5) association studies in other diseases. 
Fig. 1. A Single-strand conformation polymorphism analysis for the novel polymorphisms, showing all allelic variants for each one. B Sequencing analysis of an amplified DNA fragment showing the heterozygous genotype for each intragenic polymorphism

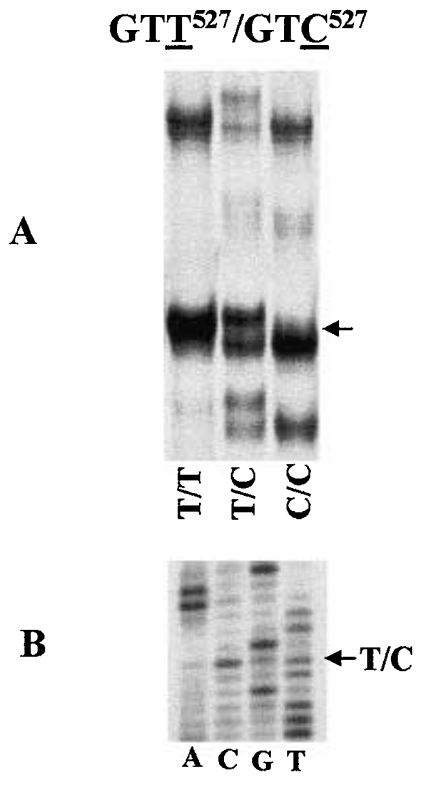

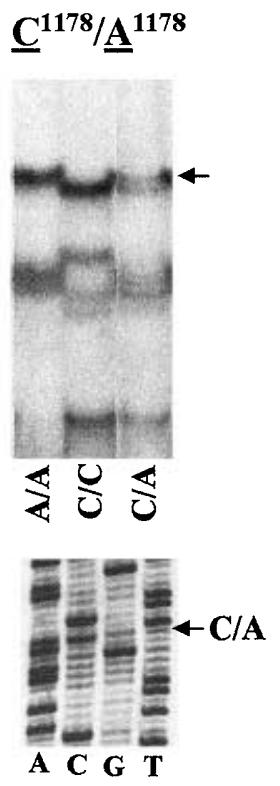
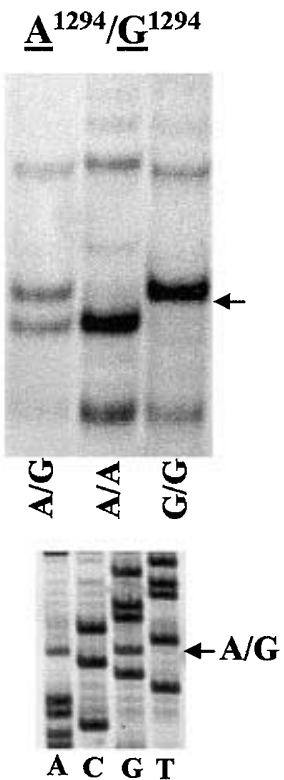

Acknowledgments We would like to thank Drs. Rui Vaz Osório and Laura Vilarinho at the Instituto de Genética Médica Jacinto Magalhães, for supplying anonymous Guthrie test cards, and Anabela Ferro, Cláudia Santos, and Mónica Santos for their cooperation in this study.

\section{References}

Coutinho P, Andrade C (1978) Autosomal dominant system degeneration in Portuguese families of the Azores Islands. Neurology 28:703709

Gaspar C, Lopes-Cendes I, Hayes S, Goto J, Arvidsson K, Dias A, Silveira I, Maciel P, Coutinho P, Lima M, Zhou Y-X, Soong B-W, Watanabe M, Giunti P, Stevanin G, Riess O, Sasaki H, Hsieh M, Nicholson GA, Brunt E, Higgins JJ, Lauritzen M, Tranebjaerg L, Volpini V, Wood N, Ranum L, Tsuji S, Brice A, Sequeiros J, Rouleau GA (2001) Ancestral origins of the Machado-Joseph disease mutation: a worldwide haplotype study. Am J Hum Genet 68:523-528

Goto J, Watanable M, Ichikawa Y, Yee Su-Bog, Ihara N, Endo K, Igarashi S, Takiyama Y, Gaspar C, Maciel P, Tsuji S, Rouleau GA, Kanazawa I (1997) Machado-Joseph disease gene products carrying different carboxyl termini. Neurosci Res 28:373-377

Ichikawa Y, Goto J, Hattori M, Toyoda A, Ishii K, Jeong S-Y, Hashida H, Masuda N, Ogata K, Kasai F, Hirai M, Maciel P, Rouleau GA,
Sakaki Y, Kanazawa I (2001) The genomic structure and expression of $M J D$, the Machado-Joseph disease gene. J Hum Genet 46:413422

Igarashi S, Takiyama Y, Cancel G, Rogaeva EA, Sasaki H, Wakisaka Y-X, Takano H, Endo K, Sanpei K, Oyake M, Tanaka H, Stevanin G, Abbas N, Dürr A, Rogaev EI, Sherrington R, Tsuda T, Ikeda M, Cassa E, Nishizawa M, Benomar A, Julien J, Weissenbach J, Wang G-X, Agid Y, St. George-Hyslop PH, Brice A, Tsuji S (1996) Intergenerational instability of the $\mathrm{CAG}$ repeat of the gene for Machado-Joseph disease (MJD1) is affected by the genotype of the normal chromosome: implications for the molecular mechanisms of the instability of the CAG repeat. Hum Mol Genet 5:923-932

Kawaguchi Y, Okamoto T, Taniwaki M, Aizawa M, Inoue M, Katayama S, Kawakami H, Nakamura S, Nishimura M, Akiguchi I, Kimura J, Narumiya S, Kakizuka A (1994) CAG expansions in a novel gene for Machado-Joseph disease at chromosome 14q32.1. Nat Genet 8:221-228

Lima M, Mayer FM, Coutinho P, Abade A (1998) Origins of a mutation: population genetics of Machado-Joseph disease in the Azores (Portugal). Hum Biol 70:1011-1023

Maciel P, Gaspar C, Guimarães L, Goto J, Lopes-Cendes I, Hayes S, Arvidsson K, Dias A, Sequeiros J, Sousa A, Rouleau GA (1999) Study of three intragenic polymorphisms in the Machado-Joseph disease gene $(M J D 1)$ in relation to genetic instability of the $(\mathrm{CAG})_{\mathrm{n}}$ tract. Eur J Hum Genet 7:147-156

Maciel P, Costa MC, Ferro A, Rousseau M, Santos C, Gaspar C, Barros J, Rouleau GA, Coutinho P, Sequeiros J (2001) Improvement in the molecular diagnosis of Machado-Joseph disease. Arch Neurol 58:1821-1827 